\title{
Hallucinations and dyskinesia with pramipexole in parkinson's disease- a case report
}

\author{
Monica Aggarwal ${ }^{1 *}$, Brahmdeep Sindhu
}

${ }^{1}$ Department of Pharmacology, ESIC Medical College and Hospital, NH3 Faridabad, India ${ }^{2}$ Department of Psychiatry, Civil Hospital, Gurgaon, India

Received: 11 June 2016 Accepted: 12 August 2016

*Correspondence to: Dr. Monica Aggarwal, Email: monicag@ rediffmail.com

Copyright: (C) the author(s), publisher and licensee Medip Academy. This is an openaccess article distributed under the terms of the Creative Commons Attribution NonCommercial License, which permits unrestricted noncommercial use, distribution, and reproduction in any medium, provided the original work is properly cited.

\begin{abstract}
Pramipexole, a dopamine agonist has a tendency to induce psychotic symptoms, when used to treat Parkinson's disease (PD). In most of the cases, patient's psychosis developed after addition of Pramipexole and exacerbated after increasing the dosage. However there has been no case report in which Pramipexole has caused psychosis at lowest starting dose without any add on drug. Here we present a case of PD in which dyskinesia and psychosis appeared with first dose of Pramipexole, as low as $0.125 \mathrm{mg}$. The patient was a 76 year old man with a one year history of PD. One year back patient observed tremors in his hand and slowing of movements. The neurologist prescribed Syndopa plus - 125, Benzhexol (schedule also same as Syndopa) and Pramipexole 0.125 $\mathrm{mg}$ at bedtime. The patient decided to start all medicines next day except Pramipexole $(125 \mathrm{mg})$ which he took at bed time. Within half an hour, patient started having visual and auditory hallucinations, along with abnormal movements and myoclonic jerks of hand, feet and mouth. He could be seen doing movements as if he is inserting needle in thread. According to him, he could visualize thieves trying to steal his car. Dechallenge with Pramipexole led to complete resolve of psychotic symptoms. After 4 weeks of therapy, there was a gradual but steady improvement in dyskinesia and tremors except slurring in speech.
\end{abstract}

Keywords: Pramipexole, Parkinson's disease, Dyskinesia, Hallucinations

\section{INTRODUCTION}

Parkinson's disease (PD) is the most common neurodegenerative movement disorder, affecting almost $1 \%$ of the population above the age of 60 years. Its early manifestation is parkinsonism, a progressive impairment of movement control including rigidity, rest tremor, and bradykinesia, while postural instability is a later feature. Non-motor symptoms caused by autonomic disturbances, dysregulation of mood and sleep, changes in cognition and behaviour, are present throughout the course of the disease and may become, in advanced stages, the most important cause of disability. The levodopa related complications prompted the development of alternative antiparkinsonian drugs, such as cathecolamine-O-methyltransferase inhibitors, monoamineoxidase-B inhibitors, and the synthetic dopamine agonists (DA). The DA present several advantages over levodopa such as direct stimulation of striatal dopaminergic neurons, longer halflife providing a more continuous stimulation at the dopamine receptors, lack of oxidative metabolites, more reliable absorption and transport. Pramipexole is a nonergotamine full agonist at the D2 subfamily of dopamine receptors, with higher selectivity for D3 than for D2 and D4 dopamine receptors. Thereby, pramipexole is able to simultaneously excite the direct striatopallidal pathway (by D3 stimulation) and to inhibit the indirect striatopallidal pathway (by D2 stimulation), alleviating PD symptoms by mimicking dopamine's effects in the striatum In addition, pramipexole has a very low affinity for 5-HT2A, 5-HT2B, and D1 receptors, partly explaining its beneficial effects in the context of cardiac 
valvulopathy and dyskinesias. ${ }^{1-4}$ Since the D3 receptors enjoy greatest predominance in the limbic system, pramipexole has the theoretical potential to also have an impact on psychiatric symptoms in PD. ${ }^{4,5} \mathrm{~A}$ metanalysis demonstrated that relative to placebo pramipexole increased the risk of hallucinations in patients with PD. ${ }^{6}$ A case report highlighted pramipexole induced olfactory hallucinations and delusions of persecution, in addition to auditory and visual hallucinations. ${ }^{7}$ In most of the cases, patient's psychosis developed after addition of pramipexole and exacerbated after increasing the dosage. However there has been no case report in which pramipexole has caused psychosis at lowest starting dose without any add on drug. Here we present a case of PD in which dyskinesia and psychosis appeared with first dose of pramipexole, as low as $0.125 \mathrm{mg}$.

\section{CASE REPORT}

The patient was a 76 year old man with a one year history of PD. One year back patient observed tremors in his hand and slowing of movements. A neighbourhood family physician prescribed him Syndopa 100 twice a day. Three months later Amantadine was added to his regimen when his symptoms did not show any improvement. Six months later, patient was dissatisfied with his progress .So the same physician added Selegiline to the regimen. After 10 days of this treatment, the patient observed slurring in his speech and inability to speak a full sentence properly. He stopped taking Selegiline. Thereafter, he went to a neurologist for consultation. The neurologist prescribed Syndopa plus(L-Dopa+Carbidopa) -125 , in divided doses four times a day; gradually increasing dose over a one month period, benzhexol (schedule also same as Syndopa) and pramipexole 0.125 $\mathrm{mg}$ at bedtime. The patient decided to start all medicines next day except pramipexole $(0.125 \mathrm{mg})$ which he took at bed time. Within half an hour, patient started having visual and auditory hallucinations, along with abnormal movements and myoclonic jerks of hand, feet and mouth. He could be seen doing movements as if he is inserting needle in thread. According to him, he could visualize thieves trying to steal his car. So he stood up vigil throughout the night outside his house. Hallucinations and dyskinesia continued next day too.

\section{Treatment}

It was decided to stop pramipexole immediately and he was prescribed a therapy with Quetiapine $25 \mathrm{mg}$ twice daily and Clonazepam $0.25 \mathrm{mg}$ to reverse the possible psychosis due to pramipexole. However his condition did not resolve. His blood pressure dipped to 100/60 $\mathrm{mmHg}$ and he was sweating. He was then admitted to the emergency. There, he was given Inj Haloperidol in DNS for two days till his psychotic symptoms subsided. On discharge, these medicines were discontinued and he was now prescribed Syndopa plus 125 for PD in four divided doses increasing gradually over a one month period. Substance-induced psychosis diagnosis was confirmed with DSM IV-TR SCID I interview, that excluded other disorders like schizophrenia, schizophreni form and/or schizoaffective disorder and acute psychotic disorder. Mood disorders with psychotic manifestations were excluded too. Brain computed tomography and magnetic resonance imaging reports excluded any organic damages. ECG, Serum electrolytes, Liver and Kidney function tests and blood glucose were within normal limits.

\section{Outcome and follow-up}

De-challenge with pramipexole and treatment with Quietiapine led to complete resolve of psychotic symptoms in two days. After 4 weeks of Syndopa and Benzhexol therapy, there was a gradual but steady improvement in dyskinesia and tremors. But slurring in speech still persited.

\section{DISCUSSION}

Pramipexole (PPX), a dopamine agonist has a tendency to induce psychotic symptoms, when used to treat Parkinson's disease (PD). The combined results of three pivotal studies showed that pramipexole, started at low initial doses and up-titrated weekly, was effective and well tolerated in mild to moderate PD. No differences in effectiveness based on age or gender were detected, and no dose-response relationship could be demonstrated. Thus, doses of $1.5 \mathrm{mg}, 3 \mathrm{mg}, 4.5 \mathrm{mg}$, and $6 \mathrm{mg} /$ day did provide similar significant benefit $t$ in reducing PD signs and symptoms compared with placebo pramipexole is generally well tolerated up to a total daily dose of $4.5 \mathrm{mg}$, both as mono-therapy and as an adjuvant to levodopa in PD patients at different disease stages. ${ }^{8,9}$

The highest dosage of $6 \mathrm{mg}$ daily led to a higher incidence of neuropsychiatric side effects, particularly somnolence, and there is generally a direct relationship between pramipexole dose and adverse events.

Adverse events that appear to occur more often with pramipexole compared with placebo are sleep disturbances, gastrointestinal symptoms (nausea, constipation), postural hypotension, peripheral edema, impulse control disorders, and hallucinosis. In studies on early PD, hallucinations occurred in $9 \%$ of pramipexoletreated patients, compared with $2.6 \%$ of patients on placebo. The same pattern was seen in advanced PD, with almost $17 \%$ of pramipexole treated patients developing hallucinations,compared with $3.8 \%$ in the placebo group. ${ }^{10,11}$ The development of hallucinations was one of the most common causes of study termination in patients with advanced PD (2.7\% on pramipexole versus $0.4 \%$ on placebo). ${ }^{8,9,11-13}$ A meta-analysis found that, compared with placebo, pramipexole was associated with a higher risk for hallucinations than ropinirole (RR 5.2) (1.9713.72) versus $2.75(0.55-13.73) .^{6}$ The risk for developing hallucinations was higher in younger patients initially treated with pramipexole, compared with younger patients 
initially treated with levodopa, but this was not seen in the older cohort. ${ }^{14}$

In our case report, the patient also experienced dyskinesia or abnormal movements after the first dose of PPX. There have been two studies comparing different dosages and other two looking at different preparations of PPX. One of the earliest investigations on PPX was carried out by the Parkinson study group, which compared four different dosages of the drug $(1.5,3.0,4.5$, and $6.0 \mathrm{mg})$ against placebo. ${ }^{8}$ Another study by the same group compared different low-dose schedules of PPX. Both did not detect any incidence of dyskinesia. Likewise, comparisons of immediate release (IR) and extended release (ER) PPX preparations failed to detect any incidence of dyskinesia symptoms in either treatment or placebo group. ${ }^{15,16}$ These active comparator studies showed that the incidence of dyskinesia events was quite similar relative to other DAAs. An L-DOPA comparison study in one cohort with long term follow-up consistently showed that PPX treatment was associated with lower risk for developing dyskinesia. These symptoms have also been reported in the placebo groups (albeit at generally lower rates), suggesting the potential involvement of non-PPX-related factors in the development of dyskinesia. ${ }^{18}$

\section{CONCLUSION}

To our knowledge this is the first case report of pramipexole-induced auditory and visual hallucinations and dyskinesia at lowest starting dose of PPX i.e 0.125 $\mathrm{mg}$. His psychosis recovered gradually after discontinuing pramipexole and applying quetiapine. This report highlights the importance of monitoring and screening the psychotic symptoms in patients treated with pramipexole, especially for elderly patients. It is still to be established whether L-DOPA treatment, PPX dosage, and other patient characteristics such as age or disease stage can play a role as contributory factors. Elucidation of such factors is likely to optimise the efficacy of antiParkinson's treatment and its compliance. To minimise the risk of psychosis, the appropriate dopaminergic drug should be administered after evaluation of a patient's epidemiological and clinical features, including personality-related factors. Specific interventions such as problem solving and communication skills training can improve social functioning of at-risk patients.

Funding: No funding sources Conflict of interest: None declared

Ethical approval: Not required

\section{REFERENCES}

1. Mierau J, Schingnitz G. Biochemical and pharmacological studies on pramipexole, a potent and selective dopamine D2 receptor agonist. Eur J Pharmacol. 1992;215:161-70.

2. Svensson K, Carlsson A, Huff RM. Behavioral and neurochemical data suggest functional differences between dopamine D2 and D3 receptors. Eur J Pharmacol. 1994;263:235-43.

3. Mierau J. Pramipexole: a dopamine-receptor agonist for treatment of Parkinson's disease. Clin Neuropharmacol. 1995;18(Suppl 1):S195-S206.

4. Bennett JP, Piercey MF. Pramipexole - a new dopamine agonist for the treatment of Parkinson's disease. J Neurol Sci. 1991;163:25-31.

5. Bouthenet ML, Souil E, Martres MP. Localization of dopamine D3 receptor mRNA in the rat brain using in situ hybridization histochemistry: comparison with dopamine D2 receptor mRNA. Brain Res. 1991;564:203-19.

6. Etminan M, Gill S, Samii A. Comparison of the risk of adverse events with pramipexole and ropinirole in patients with Parkinson's disease: a meta-analysis. Drug Safety. 2003;26:439-47.

7. Cheng-Ta Li, Tsai S, Hwang JP. Pramipexoleinduced psychosis in Parkinson's disease. Psychiatry and Clinical Neurosciences. 2008;62:245.

8. Parkinson Study Group. Pramipexole versus levodopa as initial treatment for parkinson disease: a randomized controlled trial. JAMA. 2000;284:19318.

9. Shannon KM, Bennett JP, Friedman JH. Efficacy of pramipexole, a novel dopamine agonist, as monotherapy in mild to moderate Parkinson's disease. The Pramipexole Study Group. Neurol. 1997;49:724-8.

10. Lieberman A, Ranhosky A, Korts D. Clinical evaluation of pramipexole in advanced parkinson's disease: results of a double-blind, placebo controlled, parallel-group study. Neurol. 1997;49:162-8.

11. Moller JC, Oertel WH, Koster J. Long-term efficacy and safety of pramipexole in advanced parkinson's disease: results from a European multicenter trial. Mov Disord. 2005;20:602-10.

12. Mizuno Y, Yanagisawa N, Kuno S. Randomized, double-blind study of pramipexole with placebo and bromocriptine in advanced Parkinson's disease. Mov Disord. 2003;18:1149-56.

13. Pinter MM, Pogarell O, Oertel WH. Efficacy, safety, and tolerance of the non-ergotine dopamine agonist pramipexole in the treatment of advanced parkinson's disease: a double blind, placebo controlled, randomised, multicentre study. J Neurol Neurosurg Psychiatry. 1999;66:436-4.

14. Holloway RG, Shoulson I, Fahn S. Pramipexole versus levodopa as initial treatment for parkinson disease: a 4-year randomized controlled trial. Arch Neurol. 2004;61:1044-53.

15. Kieburtz K. Safety and efficacy of pramipexole in early parkinson disease: a randomized dose-ranging study. JAMA. 1997;278:125-30.

16. Hauser RA, Schapira AH, Rascol O. Randomized, double-blind, multicenter evaluation of pramipexole extended release once daily in early parkinson's disease. Mov Disord. 2010;25:2542-9.

17. Rascol O, Barone P, Hauser RA. Efficacy, safety, and tolerability of overnight switching from immediate- 
to once daily extended-release pramipexole in early parkinson's disease. Mov Disord. 2010;25:2326-32.
18. Holloway R, Marek K, Biglan K. Long-term effect of initiating pramipexole versus Levodopa in early Parkinson disease. Arch Neurol. 2009;66:563-70.

Cite this article as: Aggarwal M, Sindhu B. Hallucinations and dyskinesia with pramipexole in parkinson's disease-a case report. Int J Basic Clin Pharmacol 2016;5:2276-9. 